\title{
A study of posterior reversible encephalopathy syndrome in patients with eclampsia
}

\author{
Seeta Garag, Mubashira Janvekar*
}

Department of Obstetrics and Gynecology, Karnataka Institute of Medical Sciences, Hubballi, Karnataka, India

Received: 09 February 2020

Accepted: 03 March 2020

*Correspondence:

Dr. Mubashira Janvekar,

E-mail: janvekarmubashira@yahoo.com

Copyright: (C) the author(s), publisher and licensee Medip Academy. This is an open-access article distributed under the terms of the Creative Commons Attribution Non-Commercial License, which permits unrestricted non-commercial use, distribution, and reproduction in any medium, provided the original work is properly cited.

\section{ABSTRACT}

Background: The association of posterior reversible encephalopathy syndrome with eclampsia has recently received a lot of attention recently. Advances in Imaging has led to better understanding of the pathophysiology of eclampsia. Present study was undertaken to study the clinical characteristics of patients with eclampsia with PRES.

Methods: This is a prospective observational study of 50 cases of Eclampsia with PRES in a period of 1 year. Patients admitted with Eclampsia were subjected to neuroimaging with CT or MRI and those with diagnosis of Posterior Reversible Encephalopathy Syndrome were included in the study and clinical profile analyzed.

Results: Total of 50 patients were studied in the period of 1 year. The average age of patients was 21.8 years, majority of them residing in rural areas (74\%) and $72 \%$ were referred cases.

Conclusions: PRES is now identified as core component of Eclampsia. More studies are required to compare the outcome of Eclampsia associated with PRES and without PRES.

Keywords: Eclampsia, Posterior reversible encephalopathy syndrome

\section{INTRODUCTION}

Posterior reversible encephalopathy syndrome is a clinicoradiological syndrome characterized by symptoms including a headache, seizures, altered consciousness and visual disturbances and radiological features of white matter vasogenic oedema. It was first described in 1996 by Hinchey et al. ${ }^{1}$ It is described in association with various conditions like hypertension, pre-eclampsia, eclampsia, infections, autoimmune diseases, cancer chemotherapy. ${ }^{2}$ Both clinical and radiological characteristics are usually reversible. ${ }^{3-5}$ PRES has recently been increasingly recognized with Eclampsia because of increased availability of brain imaging. Authors have studied the clinical characteristics of patients of eclampsia with PRES in the present study.

\section{METHODS}

The present study is a prospective observational study; it was carried out in Karnataka Institute of Medical
Sciences in Hubballi, Karnataka over a period of 1 year from June 2018 to May 2019.

\section{Inclusion criteria}

- All patients with eclampsia with PRES in antepartum period irrespective of period of gestation admitted in department of obstetrics and gynecology in KIMS Hubballi

- Patients presenting in postpartum period up to 6 weeks with diagnosis of posterior reversible encephalopathy syndrome on neuroimaging.

\section{Exclusion criteria}

- Patients with neurological complications other than eclampsia, like electrolyte disturbances, septic encephalopathy were excluded from the study

- Patients in whom neuroimaging was not done

- Patients presenting with neurological complications after 6 weeks postpartum. 
All cases were subjected to detailed history and examination. Following parameters were studied: Age, locality, parity, number of seizures, presenting complaints, period of presentation, gestational age, admission blood pressure, anticonvulsants required, type of delivery, and perinatal outcome. relevant investigations like complete blood count, coagulation profile, liver function tests, renal function tests and serum electrolytes were done. Radiological studies with CT/ MRI were done. All the necessary data was recorded in the predesigned proforma and analysed.

\section{Statistical analysis}

Analysis was done after entering the data in Microsoft excel and analysed using percentages and mean and mode.

\section{RESULTS}

A total of 50 patients diagnosed with PRES on radiological imaging were included in the study. The average age of whom was 21.8 years (Table 1), majority of whom were residing in rural area (74\%) and majority of whom were referred (72\%). 64\% were diagnosed on CT and $36 \%$ on MRI.

Table 1: Distribution of patients according to age.

\begin{tabular}{|l|l|l|}
\hline Age group (year & No. of patients & Percentage \\
\hline$<20$ & 24 & $48 \%$ \\
\hline $21-25$ & 22 & $44 \%$ \\
\hline $26-30$ & 3 & $6 \%$ \\
\hline $30-35$ & 1 & $2 \%$ \\
\hline
\end{tabular}

Table 2: Distribution according to parity.

\begin{tabular}{|l|l|l|}
\hline Parity & No. of patients & Percentage \\
\hline Primi & 33 & $66 \%$ \\
\hline Multi & 14 & $28 \%$ \\
\hline Grand multi & 3 & $6 \%$ \\
\hline
\end{tabular}

Table 3: Distribution according to onset of neurological complications.

\begin{tabular}{|l|ll|}
\hline Period & No. of patients & Percentage \\
\hline Antepartum & 19 & $38 \%$ \\
\hline Intrapartum & 1 & $2 \%$ \\
\hline Postpartum & 18 & $36 \%$ \\
\hline Antepartum+postpartum & 12 & $24 \%$ \\
\hline
\end{tabular}

\section{Presentation}

Majority of the patients were primigravida $(66 \%)$ while grand multi were only $6 \%$. This difference can be attributed to reduced number of grand multipara in general (Table 2). The distribution in the antepartum and postpartum period was almost equal (Table 3 ).
Out of 50 patients with diagnosis of PRES 46 patients presented with seizures, 2 patients with weakness and 1 with altered consciousness (Table 4).

Table 4: Presenting complaint.

\begin{tabular}{|l|ll|}
\hline Chief complaint & No. of patients & Percentage \\
\hline Seizure & 46 & $92 \%$ \\
\hline Weakness & 2 & $4 \%$ \\
\hline Altered consciousness & 1 & $2 \%$ \\
\hline Others & 1 & $2 \%$ \\
\hline
\end{tabular}

Table 5: Association with number of seizure episodes.

\begin{tabular}{|l|ll|}
\hline $\begin{array}{l}\text { Number of seizure } \\
\text { episodes }\end{array}$ & No. of patients & Percentage \\
\hline 1 & 11 & $23.9 \%$ \\
\hline $2-5$ & 25 & $54.3 \%$ \\
\hline $6-10$ & 9 & $19.6 \%$ \\
\hline$>10$ & 1 & $2.2 \%$ \\
\hline
\end{tabular}

The most common presentation was seizures (92\%) and majority of patients had 2-5 episodes. Among the 46 patients who had seizures, 25 patients had 2-5 episodes, 11 patients had only one episode of seizure, 9 patients had 6-10 episodes of seizure, and one patient had more than 10 episodes of seizure (Table 5). However, there was no mortality in any of the patients.

Table 6: In antepartum convulsions distribution according to gestational age.

\begin{tabular}{|l|l|l|}
\hline $\begin{array}{l}\text { Gestational age } \\
\text { (weeks) }\end{array}$ & No. of patients & Percentage \\
\hline$<28$ & 1 & $2 \%$ \\
\hline $29-32$ & 7 & $14 \%$ \\
\hline $33-36$ & 18 & $36 \%$ \\
\hline$>37$ & 24 & $48 \%$ \\
\hline
\end{tabular}

Among the 50 patients, majority of patients were term gestation of $>37$ weeks $(48 \%) .36 \%$ patients were between 33-36 weeks of gestation, $14 \%$ of patients between 29-32 weeks of gestation and $2 \%$ of patients less than 28 weeks of gestation (Table 6).

Table 7: Onset of post-partum convulsions.

\begin{tabular}{|lll|}
\hline Post partum & No. of patients & Percentage \\
\hline$<24$ hours & 20 & $66.7 \%$ \\
\hline $24-48$ hours & 1 & $3.3 \%$ \\
\hline 48 hours-7 days & 7 & $23.3 \%$ \\
\hline$>7$ days & 2 & $6.7 \%$ \\
\hline
\end{tabular}

Among the 50 patients thirty patients have 30 patients had seizures in the postpartum period $(18$ with postpartum eclampsia and 12 with both antepartum and postpartum eclampsia). Majority of the patients who had seizures in the postpartum period developed it within 24 
hours of delivery i.e. $66.7 \%$. This indicates strict vigilance is required within first 24 hours of delivery (Table 7).

Table 8: Admission blood pressure.

\begin{tabular}{|lll|}
\hline $\begin{array}{l}\text { Admission BP } \\
(\mathbf{m m H g})\end{array}$ & No. of patients & Percentage \\
\hline$>200 / 120$ & 0 & $0 \%$ \\
\hline $160 / 110-200 / 120$ & 23 & $46 \%$ \\
\hline $140 / 90-160 / 110$ & 20 & $40 \%$ \\
\hline$<140 / 90$ & 7 & $14 \%$ \\
\hline
\end{tabular}

Forty-six percentage of patients had blood pressure in the range of $160 / 110-200 / 120 \mathrm{mmHg}$. Whereas only 7 patients had blood pressure less than 140/90 $\mathrm{mmHg}$. None of the patients had blood pressure more than 200/120 mmHg (Table 8).

Table 9: Anticonvulsants.

\begin{tabular}{|l|ll|}
\hline Anticonvulsant & No. of patients & Percentage \\
\hline $\mathrm{MgSO}_{4}$ & 50 & $100 \%$ \\
\hline Phenytoin & 38 & $76 \%$ \\
\hline Levetiracetam & 6 & $12 \%$ \\
\hline General anaesthesia & 1 & $2 \%$ \\
\hline
\end{tabular}

Magnesium sulfate was the first line anticonvulsant given in all 50 patients. 38 patients received additional phenytoin as they had seizure even after $\mathrm{MgSO}_{4}$ administration. Leviteracetam was added in 6 patients and 1 patient required general anaesthesia to control the convulsions (Table 9).

A total $44 \%$ of patients had vaginal delivery and $56 \%$ patients were delivered by caesarean section. Caesarean section was done for obstetric indications only (Table 10).

Table 10: Delivery.

\begin{tabular}{|l|l|l|}
\hline Type of delivery & No. of patients & Percentage \\
\hline Vaginal & 22 & $44 \%$ \\
\hline Caesarean section & 28 & $56 \%$ \\
\hline
\end{tabular}

Table 11: Perinatal outcome.

\begin{tabular}{|lll|}
\hline Perinatal outcome & No. of patients & Percentage \\
\hline Still birth & 9 & $18 \%$ \\
\hline live birth & 41 & $82 \%$ \\
\hline Mother side & 26 & $63.4 \%$ \\
\hline NICU & 15 & $36.6 \%$ \\
\hline
\end{tabular}

Among the 50 patients, 9 patients had still births, 41 patients had live birth out of which 15 babies required NICU admission. There were no maternal deaths in the 50 patients (Table 11).

\section{DISCUSSION}

Eclampsia is a major cause of maternal mortality and morbidity. There is now shift occurring in the leading cause of maternal mortality and morbidity from obstetric hemorrhage to hypertensive disorders of pregnancy. Though much research is ongoing with pre-eclampsia we still have a far way to go to understand the basic pathophysiology and prevent the development of preeclampsia and eclampsia. With the availability of neuroimaging it is now possible to have a peek into the understanding of basic pathophysiology of eclampsia. PRES is now considered to be the core component of eclampsia.

The most common age group in which PRES was seen is 20-25 years. It occurs more in primigravida than multigravida. This must be because of incidence of preeclampsia and eclampsia is most commonly seen in primigravida. It was almost equally distributed among antepartum and postpartum patients. Headache was most commonly associated with PRES which is consistent with prospective study conducted by Sardesai $\mathrm{S}$ et al. ${ }^{6}$ However no mortality was seen in cases in cases of eclampsia associated with PRES.

The hypothesis proposed for development of PRES in eclampsia is rapid increase of arterial blood pressure up to hypertensive crisis or emergency. ${ }^{7}$ In this study $86 \%$ of patients had elevated blood pressure above $140 / 90 \mathrm{mmHg}$ and $14 \%$ had normal blood pressure. Management of blood pressure is an essential in treatment of PRES. ${ }^{8,9}$ Blood pressure fluctuations are to be avoided by continuous administration of antihypertensives and hemodynamic monitoring should be considered. ${ }^{10}$

The occurrence of PRES didn't increase with increase in the number of seizure episodes. Highest occurrence was seen in 2-5 episodes of seizure. This shows that the seizure frequency is not related to occurrence with PRES.

Magnesium sulfate is the drug of choice in treatment of eclampsia. In this study magnesium sulfate was used in all cases of seizures. Phenytoin was added in $76 \%$ of cases who had convulsions in spite of magnesium sulfate. $12 \%$ of patients required levetiracetam to control the seizures and 1 patient required general anesthesia. Inj mannitol was given to all cases of eclampsia. Anticonvulsants were given for 3 months on discharge.

\section{CONCLUSION}

PRES is now known to be a core component of eclampsia. It does not affect the short-term prognosis of the disease. However long-term prognosis is to be studied and further studies are required to know the incidence of eclampsia of PRES and to study the correlates of eclampsia with PRES and eclampsia without PRES. 
Funding: No funding sources Conflict of interest: None declared

Ethical approval: The study was approved by the Institutional Ethics Committee

\section{REFERENCES}

1. Hinchey J, Chaves C, Appignani B, Breen J, Pao L, Wang A, et al. A reversible posterior leukoencephalopathy syndrome. $\mathrm{N}$ Engl J Med. 1996;334:494-500.

2. Lee VH, Wijdicks EF, Manno EM, Rabintein AA. Clinical spectrum of reversible posterior leukoencephalopathy syndrome. Arc Neurol. 2008;65(2):205-10.

3. Bartynski WS. Posterior reversible encephalopathy syndrome, part 1: fundamental imaging and clinical features. AJNR Am J Neuroradiol. 2008;29(6):1036-42.

4. Garg RK. Posterior leukoencephalopathy syndrome. Postgrad Med J. 2001; 77:24-28.

5. Kastrup O, Maschke M, Wanke I, Diener HC. Posterior reversible encephalopathy syndrome due to severe hypercalcemia. J Neurol. 2002;249:1563-6.

6. Sardesai S, Dabade R, Deshmukh S, Patil P, Pawar $\mathrm{S}$, Patil A, et al. Posterior reversible encephalopathy syndrome (PRES): evolving the mystery of eclampsia. J Obstet Gynecol India. 2019;69:334.

7. Fugate JE, Rabinstein AA. Posterior reversible encephalopathy syndrome: clinical and radiological manifestations, pathophysiology, and outstanding questions. Lancet Neurol. 2015;14(9):914-25.

8. Lamy C, Oppenheim C, Mas JL. Posterior reversible encephalopathy syndrome. Handb Cli Neurol. 2014;121:1687-701.

9. Granata G, Greco A, Iannella G, Granata M, Manno A, Savastano E, et al. Posterior reversible encephalopathy syndrome - insight into pathogenesis, clinical variants and treatment approaches. Autoimmune Rev. 2015;14(9):830-6.

10. Brickman AM, Reitz C, Luchsinger JA, Manly JJ, Schupf N, Muraskin J, et al. Long-term blood pressure fluctuation and cerebrovascular diseases in an elderly cohort. Arch Neurol. 2010;67(5):564-9.

Cite this article as: Garag S, Janvekar M. A study of posterior reversible encephalopathy syndrome in patients with eclampsia. Int J Reprod Contracept Obstet Gynecol 2020;9:1691-4. 